\title{
Effects of Autonomous Community Gardening Activities in the Workplace on Job Stress, Organizational Effectiveness and Self-Esteem of Public Officials Working in Shifts
}

\author{
Tae-Kyoung Lee ${ }^{1}$ and Chang-Duck Koo ${ }^{2 *}$ \\ ${ }^{1}$ Graduate Department of Forest Therapy, Chungbuk National University, Cheongju 28644, Korea \\ ${ }^{2}$ Department of Forestry, Chungbuk National University, Cheongju 28644, Korea
}

\begin{abstract}
This study was conducted to examine effects of community gardening on job stress and job satisfaction experienced by public officials in general administration working in a 24-hour shift. The subjects were public officials at the Center for Missing Children in the Department of Women and Adolescents at the National Police Agency. The center receives initial reports of disappearance of missing children, the elderly with dementia, and people with intellectual disabilities, sends out the report to each police station, and clears the report after the missing individual is found. Twelve public officials working at the center in a double shift (full day off after a night shift, four-day interval) were grouped into four teams and total 11 of them participated in the experiment. They engaged in autonomous community gardening activities such as sowing seeds, cultivating plants, harvesting, or cooking in the workplace for five weeks from August 19 to September 22, 2018. The findings were as follows. After five weeks of autonomous gardening activities, job stress of the subjects decreased significantly. Their mean scores of job satisfaction and organizational commitment under organizational effectiveness showed a significant increase after the activities. Finally, there were significant differences in their self-esteem after participating in the gardening activities in the workplace. These results suggest that gardening activities in the workplace can help to manage job stress and quality of work life for shift workers.
\end{abstract}

Keywords: gardening in the workplace, job satisfaction, night shift work, stress reduction

\section{Introduction}

Work life of people today living in the rapidly changing information age is a series of constant stress. The excessive stress they suffer at work has a harmful influence on individual life and health, which is why there is emphasis on the importance of how to manage job stress (Park and Park, 2018). Among the 37 member countries of the OECD (2017), South Korea ranks third in working hours per worker with an annual average of 2,024 hours per year according to the 2017 data, trailing after Mexico (2,257 hours) and Costa Rica (2,179 hours). Considering that the average working hours of the OECD member countries are 1,759 hours, Korean workers have worked 265 hours more. Koreans spend a great deal of time at work, and $73.9 \%$ of men and $72.6 \%$ of women working tend to suffer greater stress at work than any other category

Received: February 15, 2019, Revised: March 5, 2019, Accepted: April 3, 2019

First author: Tae-Kyoung Lee, E-mail: cocomari@daum.net, (1) https://orcid.org/0000-0002-3634-605X

*Corresponding author: Chang-Duck Koo, E-mail: koocdm@chungbuk.ac.kr, (1) https://orcid.org/0000-0001-9508-8858 
(Statistics Korea, 2016).

All organizations expect their members to display their abilities to the fullest in order to achieve given goals, and this is perceived as a critical element that determines success or failure of organizational activities. This is why managing job satisfaction of organizational members plays a key role in effectively achieving organizational goals (Kim, 2014). In the public sector, the National Police Agency's National Center for Missing Children requires a round-the-clock shift work system. Shift work of public officials is in a rotation style that requires them to work regardless of holidays or day and night (Jung, 2007). Inevitable shift work brings physical maladjustment and obstacles to individual and family life, and night shift in particular disturbs the biorhythm and may bring sleep disorder, hypersensitivity reaction, shift-lag syndrome, mental disorder, and trouble with family and social interactions in the short term, cause work-related accidents, risks of traffic accidents and daytime sleepiness, and increase fatigue and job stress (Son, 2005). This job stress affects organizational effectiveness, and the emotional state of public officials due to job satisfaction in the public sector influences duties and organizational performance. Thus, to promote satisfaction of external customers, it is necessary to first promote job satisfaction of public officials themselves as the ones providing service (No, 2011; Na, 2013).

Self-esteem is a negative or positive evaluation of oneself, and people with self-esteem respect themselves and believe that they are valuable (Rosenberg, 1965). Since those with high self-esteem acknowledge themselves to be valuable, they have good interpersonal relations, whereas those with low self-esteem show negative emotional state and anxiety (Lee, 2009). Research findings show that higher self-esteem leads to fewer problems in interpersonal relations (Kim, 2011). Thus, finding and applying ways to improve self-esteem will help prevent or reduce negative effects of job stress (Lee and Lee, 2007).

Korea has set the goal to activate urban agriculture by 2020 , creating 7,200 urban gardens (2,700 ha) on building rooftops, school sites and unused public lands and inducing the participation of at least $10 \%$ (5 million) of the population (Roh, 2012). This study begins from the question of whether the function of urban gardens has potential and persistence in not local residents but public offices as well.

Thus, the objective of this study is to determine the effects of community gardening activities in the workplace on job stress, organizational effectiveness and self-esteem experienced by public officials in administrative service that work in night shifts at the National Police Agency's National Center for Missing Children.

\section{Research Methods}

\section{Subject}

The National Center for Missing Children is a center-unit department that receives initial reports of disappearance of missing normal children, elderly with dementia, and persons with intellectual disabilities (regardless of age), delivers the reports to each police station, and clears the reports when the missing people are found. The experiment is conducted on workers that belong to the National Center for Missing Children in the form of four-group double shifts in a four-day cycle of day shift, night shift, off duty and day off. There was the first exploration to select the spot, preparation of the garden and planting of seedlings for the experiment in May 2018. In June, the experiment was approved by the Institutional Review Board (IRB) at Chungbuk National University as project CBNU-201806-SB-646-01. We visited the center for two days on July 26 and 27 and obtained consent under the condition that the research does not interfere with off duty and day off.

The subjects were 12 public officials in general administration grouped into four teams (three subjects per team), who were in a healthy condition with physical and mental diseases but at high risk of stress and wanted to participate in the 
autonomous gardening program. There were eight subjects aged 50-59, two aged 40-49, and one aged 60; seven of them have at least 5-10 years of experience in night shift, and four had at least 11-15 years (Table 1).

\section{Implementation method of the autonomous gardening program}

Autonomous community gardening activities in the workplace included taking a walk in the garden, looking at growing plants, sowing vegetable seeds, gardening, harvesting and cooking, which were carried out for five weeks from August 19 to September 22, 2018. A garden was created in the National Police Agency's Center for Protection of Human Rights for the experiment $\left(18.2 \mathrm{~m}^{2}\right)$. Figure 1 shows an image of the program progress. Total 11 out of 12 subjects were ultimately selected for the experiment, excluding one person with insincere responses. The crops included chili pepper, eggplant, chicory, and pumpkin that were cultivated in advance for the experiment as well as radish that is familiar and easily obtainable in supermarkets. Considering the four-shift system with three persons working per day, the subjects were to observe the garden using the time they get to work, lunch hour, and time they get off work. The program was posted on the bulletin board once a week, recommending as much activity as they want and inducing their voluntary participation.

Various elements of plants were used to apply to the program. To enable the participants to visit the garden freely out of their own will, the activities were organized as shown in Table 2: sowing radish seeds in Week 1, gardening or cultivating in Weeks 2 and 3, harvesting in Week 4, and cooking in Week 5.

Table 1. Characteristics of the participants in this study $(\mathrm{N}=11)$

\begin{tabular}{|c|c|c|c|}
\hline Characteristic & Division & $\mathrm{n}$ & Percent $(\%)$ \\
\hline \multirow{2}{*}{ Gender } & Male & 0 & 0.0 \\
\hline & Female & 11 & 100.0 \\
\hline \multirow{4}{*}{ Age } & 30 to 39 & 0 & 0.0 \\
\hline & 40 to 49 & 2 & 18.1 \\
\hline & 50 to 59 & 8 & 72.7 \\
\hline & 60 or more & 1 & 9.1 \\
\hline \multirow{5}{*}{ Night shift experience in years } & Less than 5 years & 0 & 0.0 \\
\hline & 5 to 10 years & 7 & 63.6 \\
\hline & 11 to 15 years & 4 & 36.4 \\
\hline & 16 to 20 years & 0 & 0.0 \\
\hline & More than 20 years & 0 & 0.0 \\
\hline \multirow{2}{*}{ Marital status } & Married & 8 & 72.7 \\
\hline & Others $^{z}$ & 3 & 27.3 \\
\hline \multirow{4}{*}{ Educational background } & Middle school & 0 & 0.0 \\
\hline & High school & 3 & 27.3 \\
\hline & University & 6 & 54.5 \\
\hline & Graduate or above & 2 & 18.2 \\
\hline
\end{tabular}

${ }^{\mathrm{z}}$ Others: never been married, divorced or widowed. 


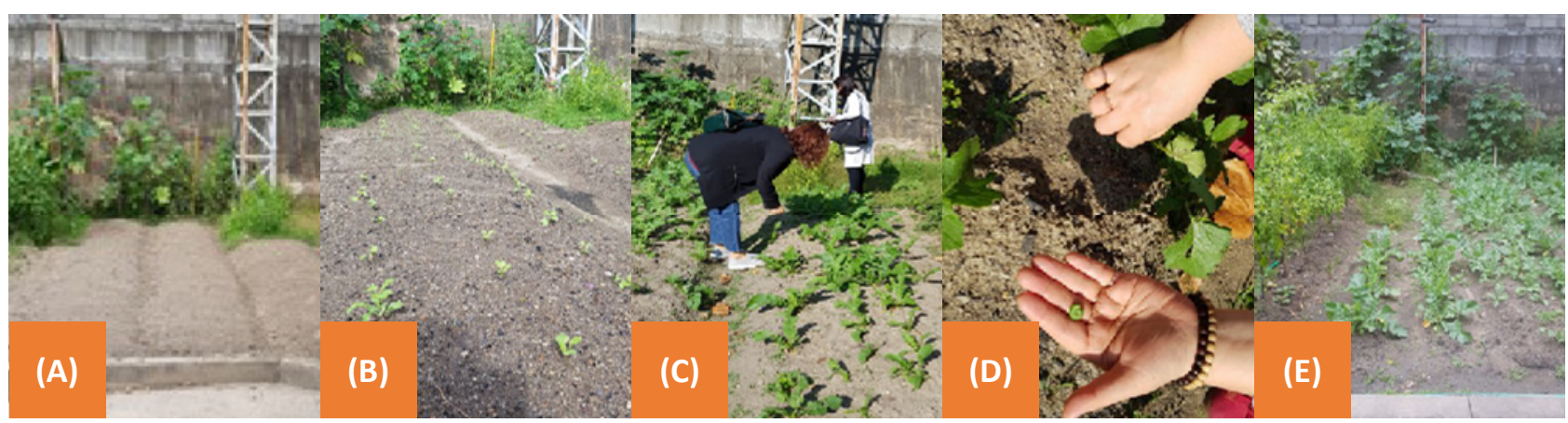

Figure 1. Pictures of a newly created community garden (A), plants growing (B), participants observing plants growth (C), performing pest control and harvesting vegetables (D), fully grown vegetables before harvest (E).

Table 2. Contents of gardening activities in the program

\begin{tabular}{lll}
\hline Session (Date) & Program & \multicolumn{1}{c}{ Activities } \\
\hline Week 1 (August 18) & Sowing \& planting & Sowing radish seeds (team activities), watering, weed control, observing plants grow \\
Week 2 (August 26) & Gardening activities & Watering, weed removal, pest control, observing plants grow \\
Week 3 (September 2) & Gardening activities & Watering, weed removal, pest control, observing plants grow \\
Week 4 (September 9) & Harvesting activities & $\begin{array}{l}\text { Harvesting vegetables, gift wrapping, weed control, observing plants grow, } \\
\text { cooking with office colleagues }\end{array}$ \\
Week 5 (September 16) & Cooking activities & Harvesting vegetables, cooking with family \\
\hline
\end{tabular}

\section{Measurement tool}

Job stress was measured using 25 items of the shortened form of Korea Occupational Stress Scale (KOSS-SF), which showed Cronbach's $\alpha=.77$. For organizational effectiveness, total 10 items (five items of job satisfaction and five items of organizational commitment) used in the study by Shin and Lee (2013) were applied to this study. Job satisfaction showed Cronbach's $\alpha=.62$ and organizational commitment showed Cronbach's $\alpha=.72$. Self-esteem was measured using 10 items of the Self-Esteem Scale developed by Rosenberg (1965) and adapted by Jeon (1974), which showed Cronbach's $\alpha=.66$.

\section{Statistical analysis}

Frequency analysis was conducted on the general characteristics of individual subjects displayed in percentile, and the difference of the experimental group before and after the gardening activities was analyzed by Wilcoxen matched pairs signed rank test using SPSS Statistics 18.0 Program, with the significance level of $p<.05$.

\section{Results and Discussion}

\section{Gardening activities of subjects}

With four shifts in five weeks of the experiment, we considered that the subjects would be working for three to four days a week, with three persons per team working per day. To the question of how often they used the garden on their way to work, in the lunch hour and after they got off work, most of the (six subjects, 54.5\%) responded that they visited 2-3 times 
a week, followed by four subjects (36.4\%) who visited 4-6 times a week, and one subject (9.1\%) who visited only once a week (Table 3). To the question of how long they usually stayed at the garden, eight subjects $(72.7 \%$ ) responded that they stayed for less than 30 minutes, followed by two subjects (18.2\%) who stayed for 30 minutes to less than one hour, and one subject $(9.1 \%)$ who stayed for one hour to less than two hours. When asked how many joined in gardening activities, one subject $(9.1 \%)$ responded that he/she was alone $(9.1 \%)$, six subjects responded that two people went together (54.5\%), two subjects responded that three people went together (18.2\%), and two subjects responded that four people went together (18.2\%). For the most preferred gardening activity, six subjects (54.5\%) responded that it was gardening, three subjects $(27.3 \%)$ responded it was cooking, and two subjects (18.2\%) responded that it was harvesting.

\section{Job stress and job satisfaction}

As a result of conducting posttest and pretest after five weeks of autonomous gardening activities with 11 subjects working at the center, job stress decreased significantly (Table 4). The mean of job stress in the pretest was 75.36, which

Table 3. Overall analysis of gardening activities questionnaire

\begin{tabular}{|c|c|c|c|}
\hline Question & Answer & $\mathrm{n}$ & Percent $(\%)$ \\
\hline \multirow{2}{*}{ Do you have any experience in agriculture? } & Yes & 5 & 45.5 \\
\hline & No & 6 & 54.5 \\
\hline \multirow{3}{*}{ Where are you from? } & A big city & 8 & 72.7 \\
\hline & The rural & 3 & 27.3 \\
\hline & A small city & 0 & 0.0 \\
\hline \multirow{5}{*}{ How many times did you visit and work in the garden? } & Daily & 0 & 0.0 \\
\hline & 4 6 times a week & 4 & 36.4 \\
\hline & 2-3 times a week & 6 & 54.5 \\
\hline & Once a week & 1 & 9.1 \\
\hline & 2-3 times a month & 0 & 0.0 \\
\hline \multirow{4}{*}{ How much time did you spent in the garden per visit? } & Less than 30 minutes & 8 & 72.7 \\
\hline & 30 minutes to 1 hour & 2 & 18.2 \\
\hline & 1 to 2 hours & 1 & 9.1 \\
\hline & 2 to 3 hours & 0 & 0.0 \\
\hline \multirow{6}{*}{ How many people worked in the garden when you visit? } & 1 & 1 & 9.1 \\
\hline & 2 & 6 & 54.5 \\
\hline & 3 & 2 & 18.2 \\
\hline & 4 & 2 & 18.2 \\
\hline & 5 & 0 & 0.0 \\
\hline & 6 & 0 & 0.0 \\
\hline \multirow{4}{*}{ What is your favorite activity among the programs? } & Cooking activities & 3 & 27.3 \\
\hline & Gardening activities & 6 & 54.5 \\
\hline & Harvesting vegetables & 2 & 18.2 \\
\hline & Transplanting & 0 & 0.0 \\
\hline
\end{tabular}


decreased by 18.63 down to 56.73 in the posttest, showing the significance probability of .00. The negative thoughts about occupational climate showed a remarkable improvement in the posttest, and the subjects also had positive views about the organizational system as well (Table 5).

The pretest mean of job satisfaction was 14.18 and the posttest mean increased by 4.18 up to 18.36 . The mean of organizational commitment increased from 14.09 in the pretest by 3.81 up to 17.90 in the posttest, showing a statistically significant change (Table 6).

Table 4. Pre- and post-test comparison in overall job stress

\begin{tabular}{lccccc}
\hline Division & $\mathrm{N}$ & $\mathrm{M}$ & $\mathrm{SD}$ & $\mathrm{Z}^{\mathrm{z}}$ & $p$ \\
\hline Pre & 11 & 75.36 & 4.71 & $-2.94^{\mathrm{a}}$ & $.00^{*}$ \\
Post & 11 & 56.73 & 5.04 & \\
\hline
\end{tabular}

${ }^{\mathrm{z}}$ Wilcoxon signed rank test was used to analyze differences within the group.

${ }^{\mathrm{a}}$ Based on negative ranks.

${ }^{\mathrm{b}}$ Based on positive ranks.

* $p<.05$.

Table 5. Pre- and post-test comparison in subcategories of job stress

\begin{tabular}{|c|c|c|c|c|c|c|}
\hline \multirow{2}{*}{ Division } & \multicolumn{2}{|c|}{ Pre } & \multicolumn{2}{|c|}{ Post } & \multirow{2}{*}{$\mathrm{Z}^{\mathrm{z}}$} & \multirow{2}{*}{$p$} \\
\hline & M & SD & M & SD & & \\
\hline Job demand & 12.9 & 0.70 & 10.5 & 1.63 & $-2.68^{\mathrm{a}}$ & $.00^{*}$ \\
\hline Insufficient job control & 10.6 & 1.12 & 8.1 & 1.57 & $-2.82^{\mathrm{a}}$ & $.00^{*}$ \\
\hline Interpersonal conflict & 8.9 & 0.94 & 6.9 & 1.04 & $-3.02^{\mathrm{a}}$ & $.00^{*}$ \\
\hline Job insecurity & 7.3 & 0.67 & 5.7 & 0.78 & $-3.03^{\mathrm{a}}$ & $.00^{*}$ \\
\hline Organizational system & 11.7 & 1.55 & 8.5 & 1.86 & $-2.81^{\mathrm{a}}$ & $.00^{*}$ \\
\hline Lack of reward & 9.2 & 0.90 & 6.2 & 0.60 & $-2.98^{a}$ & $.00^{*}$ \\
\hline Occupational climate & 14.6 & 1.20 & 10.6 & 1.20 & $-2.98^{\mathrm{a}}$ & $.00^{*}$ \\
\hline
\end{tabular}

${ }^{\mathrm{z}}$ Wilcoxon signed rank test was used to analyze differences within the group.

${ }^{\mathrm{a}}$ Based on negative ranks.

${ }^{\mathrm{b}}$ Based on positive ranks.

${ }^{*} p<.05$.

Table 6. Pre- and post-test comparison in job satisfaction and organizational commitment

\begin{tabular}{lllllll}
\hline Division & & $\mathrm{N}$ & $\mathrm{M}$ & $\mathrm{SD}$ & $\mathrm{Z}^{\mathrm{z}}$ & $p$ \\
\hline \multirow{2}{*}{ Job satisfaction } & Pre & 11 & 14.18 & 1.88 & $-2.97^{\mathrm{b}}$ & $.00^{*}$ \\
& Post & 11 & 18.36 & 2.27 & 2.70 & \\
Organizational commitment & Pre & 11 & 14.09 & 1.58 & $-2.68^{\mathrm{b}}$ & $.00^{*}$ \\
& Post & 11 & 17.90 & & \\
\hline
\end{tabular}

${ }^{\mathrm{z}}$ Wilcoxon signed rank test was used to analyze differences within the group.

${ }^{\mathrm{a}}$ Based on negative ranks

${ }^{\mathrm{b}}$ Based on positive ranks.

${ }^{*} p<.05$. 
Table 7. Pre- and post-test comparison in self-esteem

\begin{tabular}{|c|c|c|c|c|c|c|}
\hline Division & & $\mathrm{N}$ & M & SD & $\mathrm{Z}^{\mathrm{Z}}$ & $p$ \\
\hline \multirow{2}{*}{ Self-esteem } & Pre & 11 & 32.37 & 2.46 & \multirow{2}{*}{$-2.45^{b}$} & \multirow{2}{*}{$.01^{*}$} \\
\hline & Post & 11 & 34.82 & 2.89 & & \\
\hline \multirow{2}{*}{ Positive self-esteem } & Pre & 11 & 12.45 & 2.11 & \multirow{2}{*}{$-2.96^{\mathrm{b}}$} & \multirow{2}{*}{$.00^{*}$} \\
\hline & Post & 11 & 16.02 & 1.34 & & \\
\hline \multirow{2}{*}{ Negative self-esteem } & Pre & 11 & 15.72 & 1.42 & \multirow{2}{*}{$-2.94^{b}$} & \multirow{2}{*}{$.00^{*}$} \\
\hline & Post & 11 & 15.67 & 1.72 & & \\
\hline
\end{tabular}

${ }^{\mathrm{z}}$ Wilcoxon signed rank test was used to analyze differences within the group.

${ }^{\mathrm{a}}$ Based on negative ranks.

${ }^{\mathrm{b}}$ Based on positive ranks.

${ }^{*} p<.05$.

\section{Self-esteem}

Self-esteem before and after the gardening activities in the workplace showed a significant difference from 32.37 in the pretest to 34.82 in the posttest, showing an increase of 2.45 (Table 7). This indicated that there were more positive questions that affected the formation of positive self-esteem.

\section{Conclusion}

This study was conducted to determine the effects of autonomous gardening on job stress, organizational effectiveness and self-esteem on members of a center-unit department in the police organization working in night shifts. There was the selection of the spot, preparation of the garden and planting of seedlings for the experiment with 11 workers working in four-group double shifts (day shift, night shift, off duty and day off/four-day cycle). The crops selected were chili pepper, eggplant, chicory, and pumpkin that were cultivated in advance and sowed radish that can be cultivated. Considering the night shift, the subjects were to observe the garden using the time they get to work, lunch hour, and time they get off work. The activity program was posted on the bulletin board once a week, recommending as much activity as they want and inducing their voluntary participation. The experiment was carried out for five weeks from August 19 to September 22, 2018, and the pretest-posttest surveys were conducted. Most of the subjects (seven subjects, 63.6\%) worked for at least 5-10 years in the current department (night shift), and six subjects (54.5\%) most preferred gardening. After the program, job stress decreased significantly from 75.36 in the pretest to 56.73 in the posttest, showing a remarkable decrease of 18.63. More specifically, the subjects showed positive responses about occupational climate and organizational system. Interpersonal conflict and job insecurity showed little change, showing the same results as the studies by Lee (2017), Lim (2017) and Vienneau et al., (2017), which is similar to the research argument by Choi et al. (2015). Organizational effectiveness, or job satisfaction, showed a statistically significant difference from 14.18 before the program to 18.36 after the program, and job commitment increased significantly from 14.09 to 17.90. Self-esteem that brings satisfaction with life showed a statistically significant difference from 32.37 before the program to 34.82 after the program. This led to the significant conclusion that autonomous gardening activities enable people to manage their own job stress and increase organizational effectiveness and self-esteem. 


\section{References}

Choi, Y.H., S.Y. Yun, and B.J. Choi. 2015. Effects of horticultural activity on job stress, coping ability, and job satisfaction of elementary school teachers. J. Korean Soc. People Plants Environ. 18(4):327-331. https://doi.org/10.11628/ksppe.2015.18.4.327

Jeon, B.J. 1974. Self-esteem: A test of its measurability. J. Yonsei 11:107-130.

Jung, W.I. 2007. A study on the factors that have an effect on police officers' fatigue. Doctoral dissertation, Dongguk University, Seoul, Korea.

Kim, H.J. 2011. A study on the effects of Self-esteem on job satisfaction and service orientation in Korean flight attendants. Master's thesis, Silla University, Busan, Korea.

Kim, K.J. 2014. The influence of Korean regional police officer's emotional labor on organizational effectiveness focus on psychological aspects of organizational effectiveness. Master's thesis, Seoul National University, Seoul, Korea.

Lee, B.I. and S.Y. Lee. 2007. An effect of self-esteem on organizational effectiveness in sports centers instructor. J. Coach. Dev. 9(2):441-450.

Lee, S.H. 2009. The relation among the working situation, job satisfaction, and self-esteem among workers at residential facilities. Master's thesis, Ewha Womans University, Seoul, Korea.

Lee, W.S. 2017. A study on evaluating the diverse value of urban agriculture and its activation plan. Doctoral dissertation, Seoul National University, Seoul, Korea.

Lim, C.H. 2017. The impact of police officers' job stress dimension on organizational citizenship behavior. J. Korean Assoc. Police Sci. 65:163-196.

Na, Y.C. 2013. The effect of police officers' job stress on their behavior : Focused on the relationship between job stress and job satisfaction, organizational commitment, organizational attachment, and loyalty. Doctoral dissertation, Hanyang University, Seoul, Korea.

No, Y.H. 2011. The effect of job stress of regional government employees on job satisfaction and organizational commitment: Focused on adjustment-prevention-solution effects according to social support. Master's thesis, Catholic University, Incheon, Korea.

OECD. 2017. OECD employment outlook 2017. Paris: OECD Publishing. https://doi.org/10.1787/empl_outlook-2017-en

Park, S.Y. [Sook Young] and S.Y. [So Yeon] Park. 2018. Influence of job stress factors on job satisfaction among local officials: Mediating effect of depression. Korean J. Local Gov. Stud. 21(4):123-142. https://doi.org/10.20484/klog.21.4.6

Roh, H.Y. 2012. A study on the influencing factors of urban community garden for the activation of community. Master's thesis, Seoul National University, Seoul, Korea.

Rosenberg, M. 1965. Society and the adolescent self-image. Princeton, NJ: Princeton University Press.

Shin, H.Y. and H.S. Lee. 2013. An analysis of a structural causal relationship among organizational justice, organizational commitment, and innovational behavior. Korean Public Adm. Rev. 47(3):157-179.

Son, K.H. 2005. Daytime sleepiness and fatigue in adult men according to shift work. Master's thesis, Seonam University, Namwon, Korea.

Statistics Korea. 2016. 2016 Social survey. Retrieved from http://kostat.go.kr.

Vienneau, D., K. de Hoogh, D. Faeh, M. Kaufmann, M. Wunderli, and M. Röösli. 2017. More than clean air and tranquillity: Residential green is independently associated with decreasing mortality. Environ. Int. 108:176-184.

https://doi.org/10.1016/j.envint.2017.08.012 